\title{
FEATURES OF CRYSTALLIZATION OF HIGH-ALLOY ALUMINUM IRON AND FORMATION OF ITS STRUCTURE
}

\author{
${ }^{1}$ Edis B. TEN, ${ }^{2}$ Irina B. HER, ${ }^{3}$ Alexander S. DROKIN \\ ${ }^{1}$ National University of Science and Technology “MISIS, Moscow, Russia, edis ten@mail.ru \\ ${ }^{2}$ Sun Steel Co., Ltd, Gyeonggi-Do, Republic of Korea, irina1her@gmail.com \\ ${ }^{3}$ RUSAL, Moscow, Russia
}

https://doi.org/10.37904/metal.2021.4070

\begin{abstract}
The crystallization features of nodular cast iron alloyed with 19-25\% Al have been investigated. Using the Thermo-Calc computer program, polythermal sections of the phase diagrams of the quaternary $\mathrm{Fe}-\mathrm{Al}-\mathrm{C}-\mathrm{Si}$ system were obtained on an aluminum scale from 0 to $40 \%$ with varying carbon and silicon contents between $1.5-2.5$ and $1.0-2.0 \%$, respectively. The obtained results allowed us to identify the sequence of phase transformations during primary and secondary crystallization of cast iron. It has been established that the crystallization of cast iron begins with the separation of primary graphite crystals from the liquid phase. Then, a double eutectic crystallizes, consisting of a solid solution based on aluminum-doped ferrite and graphite ( $\alpha$ + CGr). With an increase of silicon content to $2 \%$, a triple eutectic appears, consisting of aluminum alloyed with ferrite, graphite and aluminum carbide $\mathrm{Al}_{4} \mathrm{C}_{3}\left(\alpha+\mathrm{CGr}+\mathrm{Al}_{4} \mathrm{C}_{3}\right)$. After that, the maximum alloyed with aluminum ferrite is released from the remainder of the liquid phase. Upon subsequent cooling of cast iron due to a decrease in the solubility of aluminum and carbon in the a phase, Al4C3 carbide is released from it. These data are consistent with the results of thermographic studies. The study of the structure of sand cast iron castings, showed that it generally corresponds to expectations of polythermal sections and thermographic analysis. But different in details. So, in cast iron, instead of the expected $\mathrm{Al}_{4} \mathrm{C}_{3}$ carbide, iron - aluminum carbide is formed, which is close with composition to $\mathrm{Fe}_{1.5} \mathrm{AlC}_{\mathrm{x}}$.
\end{abstract}

Keywords: Aluminum cast iron, crystallization, phase transformations, structure

\section{INTRODUCTION}

Highly alloyed alloys in which expensive chromium and nickel are the alloying elements are widely used as heat-resistant materials $[1,2]$. However, the life of working parts made by heat-resistant alloys is limited, and as higher the working temperature as shorter it is. This leads to increasing of costs for maintaining the units in working condition. In this regard, reducing the cost of heat-resistant products while increasing or maintaining their performance, including service life, is becoming a very urgent task.

One of the promising variants is the manufacture of such parts from cast iron with spherical graphite alloyed by $19-25 \%$ of Aluminum [1,3,4]. Castings from such cast iron are heat resistant at high temperatures both in air (up to $1100^{\circ} \mathrm{C}$ ) and in environments containing sulfur, sulfur dioxide, vanadium oxides and water vapor. In addition, they can functionally work as wear-resistant products having high strength at normal and high temperatures. Moreover, it is easier and cheaper than castings from high alloy chromium and chromium-nickel steels and cast irons of a similar purpose.

Previous studies [1,3-10] made it possible to establish the influence of components on the structure and properties of cast iron, to evaluate its casting and operational properties, to develop technological parameters of melting, casting, and heat treatment of castings. However, at present, the potential of high-alloyed aluminum 
cast iron is not fully realized. One of the constraining factors is the insufficient knowledge of the laws of its crystallization and structure formation. Therefore, the present work is devoted to the study of these aspects.

\section{EXPERIMENTAL PROCEDURE}

The object of the study was high-alloy aluminum cast iron with the following content of components, $\%$ of mass: 1.6-2.5 C; $1.0-2.0 \mathrm{Si} ; 19.0-25.0 \mathrm{Al} ; \leq 0.8 \mathrm{Mn} ; \leq 0.03 \mathrm{~S} ; \leq 0.02 \% \mathrm{P}$. Cast iron was melted in an induction crucible furnace with a main lining. At the same time, pig iron and steel scrap were used as the basic filling charge. After their melting, the liquid metal was superheated to a temperature of $1480-1500{ }^{\circ} \mathrm{C}$ and alloyed with aluminum. Before melt releasing, spheroidizing modification of liquid cast iron was carried out by adding mischmetal to the furnace ( $\sum$ Rare-earth metals $\approx 97 \% ; \mathrm{Ce} \approx 55 \%$ ). Then, during the discharging of cast iron into the ladle, it was graphitized by supplying Fe-75Si ferrosilicon to a metal stream.

Phase transformations during crystallization were studied by polythermal sections of Fe-Al-C-Si systems obtained using the Thermo - Calc software package (TCW-4 version, TCFE4 database) [11]. Thermal analysis was carried out by taking the melt cooling curve using a tungsten-rhenium thermocouple. The potentiometer data was processed using the mathematical program Microsoft Excel. The obtained cooling curves were used to determine the temperatures of liquidus, eutectic crystallization, and solidus.

Metallographic studies were carried out on a Neophot 21 microscope from ZEISS JENA at various magnifications/

Microhardness was measured on a Wilson Wolpert Micro-Vickers 402MVD instrument at a load of $1 \mathrm{~kg}$.

X-ray spectral analysis was performed on a JSM - 35CF electron microscope with a double spectrum.

\section{RESULT AND DISCUSSION}

Using a Thermo-Calc computer program, polythermal sections of the quaternary diagrams of the Fe-Al-C-Si system were constructed on an Aluminum scale from 0 to $40 \%$. In this case, the Carbon and Silicon contents were varied in the range of $1.5-2.5$ and $1.0-2.0 \%$, respectively. As example, one of the constructed polythermal sections is shown in Figure 1.

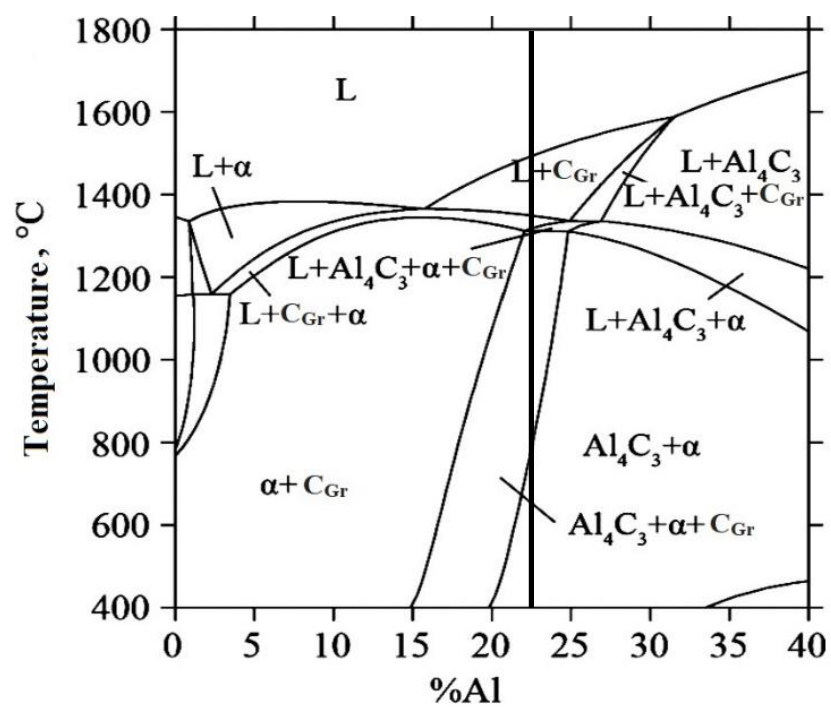

Figure 1 Polythermal sections of system diagrams $\mathrm{Fe}-\mathrm{Al}-2.0 \% \mathrm{C}-1.5 \% \mathrm{Si}$

The polythermal sections shows, that the crystallization of cast iron, containing $2 \% \mathrm{C}, 1.5 \% \mathrm{Si}$ and $22.5 \% \mathrm{Al}$, begins with the separation of primary graphite crystals from molten iron. Then, a double eutectic crystallizes 
and consists of a solid solution based on aluminum-alloyed ferrite and graphite ( $\alpha+C G r)$. On other polythermal sections constructed at $2 \% \mathrm{Si}$, appears a triple eutectic, consisting of aluminum alloyed with Ferrite, Graphite, and Aluminum carbide $\mathrm{Al}_{4} \mathrm{C}_{3}\left(\alpha+\mathrm{CGr}+\mathrm{Al}_{4} \mathrm{C}_{3}\right)$. After that, the maximum alloyed with aluminum Ferrite ( $\alpha-$ phase) is released from the remainder of the liquid phase. At subsequent cooling of cast iron due to a decreasing of the solubility of aluminum in the $\alpha$-phase $+\mathrm{Al}_{4} \mathrm{C}_{3}$ carbide is released from it.

These data are consistent with the result of thermographic studies. Cast iron mainly crystallized at as constant temperature but undergoes slight pre-Eutectic and post-Eutectic crystallization. On the temperature-time curve, it is possible to identify the areas of cooling of molten iron, pre-Eutectic crystallization of primary Graphite, Eutectic crystallization, post-Eutectic crystallization of Ferrite ( $\alpha$-phase), cooling of solid Cast iron and discharging of Aluminum containing a carbide phase from a supersaturated solid solution ( $\alpha$-phase).

A comparison of critical temperature crystals and experimental results shows that actual temperature crystallizations are significantly lower than theoretical values. Apparently, this is due to the difficulty of discharging the graphite phase in the form of primary crystals and the associated strong supercooling of the melt.

The formation of the structure of cast iron was studied considering the above results of phases, their sequence, combinations, and temperatures they release during the transition of high-alloyed Aluminum Cast iron from a liquid to a solid state.

The large length of the horizontal section on the cooling curve indicates the development of eutectic crystallization and the formation of structures in the structures. According to the cooling and polythermal section curves, the composition should contain three structural components: the inclusion of primary Graphite (I), Graphite-Ferritic eutectic (II), and secondary carbide $\mathrm{Al}_{4} \mathrm{C}_{3}$ (III) released after eutectic crystallization. However, the real structure is different from the above.

Figure 2 shows a typical microstructure of cast iron. In not etched samples (Figure 2, a), dark inclusions of spherical Graphite uniformly distributed in a metal matrix are distinguished. In the matrix itself, the main light phase and the line inclusions of dark color are distinguished. In the etched form, at a high magnification in the center of the dark phase, a graphite inclusion is detected, which is located on a white background around fenced dark stitch inclusions of a fancy shape (Figures 2, b)
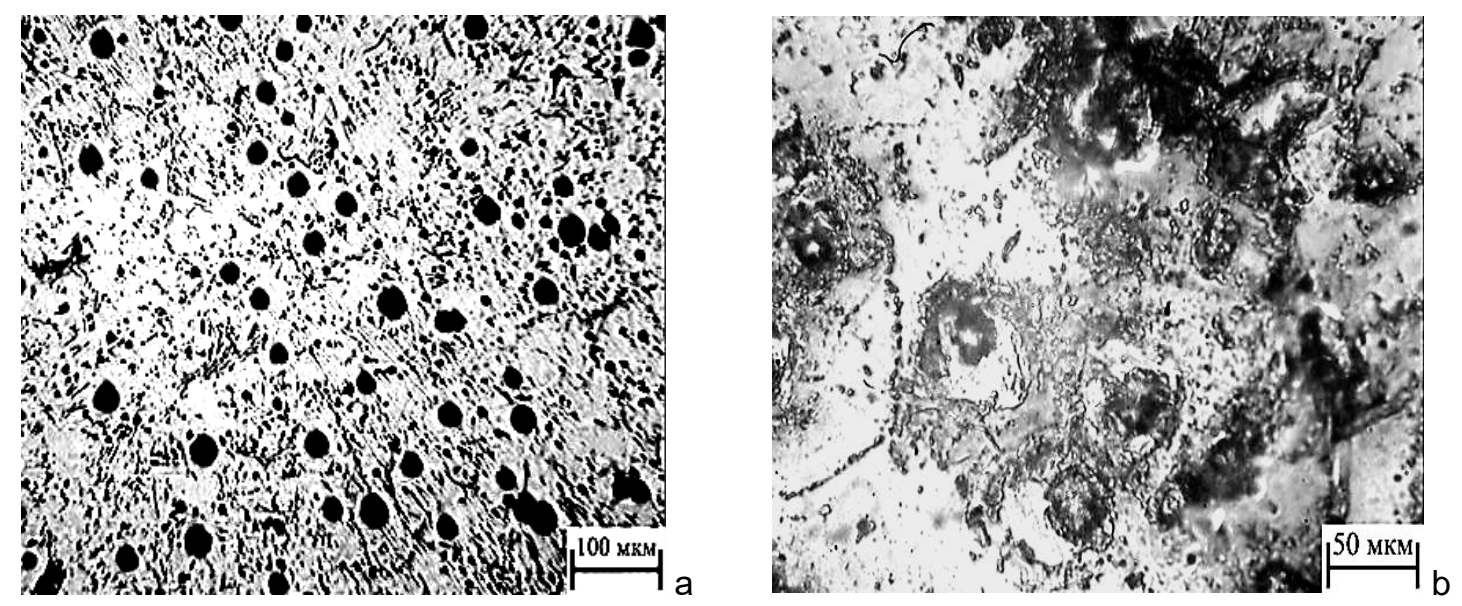

Figure 2 The structure of Aluminum (22\%) alloyed Cast Iron with spherical Graphite before (a) and after etching (b)

The light and dark phases were previously identified by measuring their microhardness and comparing the obtained values with published data. The microhardness of the light phase is $413 \mathrm{HV}$, which corresponds to the microhardness of aluminum-alloyed ferrite ( $\alpha$-phase). The darker crystalline phase has a microhardness 
of $650 \mathrm{HV}$; therefore, it was identified as Iron - Aluminum carbide Fe3AICx ( $\varepsilon$ - phase), the microhardness of which is in the range of $680-760 \mathrm{HV}$ [1].

The phase compositions were additionally studied by using an electron microscope with a microanalyzer. Received results are shown in Figure 3. A quantitative analysis confirms that the metal matrix "a" of cast iron ( $\alpha$ phase) is a ferrite alloyed with Aluminum up to $\sim 23 \%$ of the mass, dark inclusions of round shape "c" are Graphite CGr, and there is a gray phase "b" that contains Iron, Aluminum and Carbon and therefore can be considered as Iron-Aluminum carbides. However, according to multiple determinations, the atomic fractions of Iron there are only 1.3-1.6 times higher than the atomic fraction of Aluminum. Therefore, they, most likely, are iron-aluminum carbides of variable composition of the FeyAlCx type, where $y=1.3 \div 1.6$.
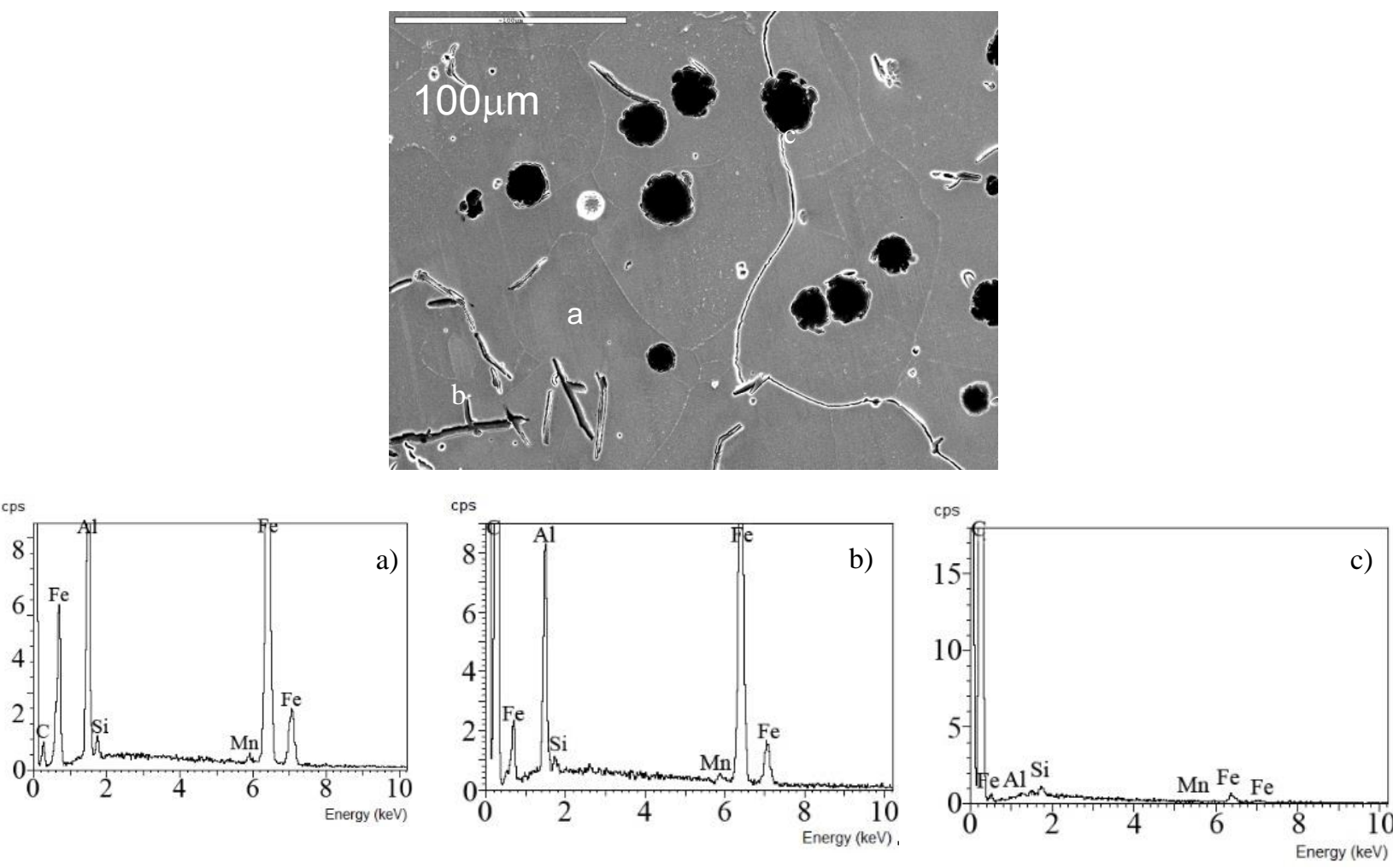

Figure 3 - Results of X-ray spectral phase analysis of Aluminum (22\%) alloyed Cast Iron with spherical Graphite

The actual structure of Cast Iron differs from expected one in several ways. First, it is not possible to unambiguously identify primary Graphite inclusions. In addition, instead of the expected $\mathrm{Al}_{4} \mathrm{C}_{3}$ carbide, the Iron-Aluminum carbide is formed in Iron, that is close to $\mathrm{Fe}_{1.5} \mathrm{AlC}_{\mathrm{x}}$ composition. It is possible, under conditions of high supercooling, that it is thermodynamically more profitable to form triple carbide, instead of double $\mathrm{Al}_{4} \mathrm{C}_{3}$ carbide, not even $\mathrm{Fe}_{3} \mathrm{AICx}$ ( $\varepsilon$ - phase), but Fe ${ }_{1.5} \mathrm{AlC}$. Accordingly, when compared with the polythermal sections of the quaternary $\mathrm{Fe}-\mathrm{Al}-\mathrm{C}-\mathrm{Si}$ system, it can be assumed that with an increase of the silicon content from 1 to $2 \%$, iron-aluminum carbide may precipitate from the triple eutectic.

\section{CONCLUSION}

The performed studies substantially complement our knowledge of the laws of crystallization of high-alloyed Aluminum cast iron and the formation of its structure. It has been established that crystallization of cast iron containing $19-25 \%$ Al begins with the separation of primary Graphite crystals from the liquid phase. Then crystallization of the double Eutectic ( $\alpha+C G r)$ occurs. With an increase in the amount of Silicon to $2 \%$, a triple Eutectic appears $\left(\alpha+\mathrm{CGr}+\mathrm{Al}_{4} \mathrm{C}_{3}\right)$. After that, the maximum Aluminum-alloyed Ferrite is released from the 
remainder of the Liquid phase. Upon subsequent cooling of cast iron due to a decrease of the solubility of Aluminum and Carbon in the $\alpha$-phase, $\mathrm{Al}_{4} \mathrm{C}_{3}$ Carbide is released from it. These data are consistent with the results of thermographic studies. A study of the structure of sand Cast Iron castings, showed that it generally corresponds to the expectations of polythermal sections and thermographic analysis. But different in details. So, in cast iron, instead of the expected $\mathrm{Al}_{4} \mathrm{C}_{3}$ carbide, Iron - Aluminum carbide is formed, which is close in composition to $\mathrm{Fe}_{1.5} \mathrm{AlC}$.

\section{REFERENCES}

[1] ALEKSANDROV, N.N., KLOCHNEV, N.I. Production technology and properties of heat-resistant cast irons. Moscow: Mechanical Engineering, 1964. p. 171.

[2] KOLOKOLTSEV, V.M., SOLOVIEV, V.P., MOLOCHKOV, P.A., POTAPOV, M.G. Castings from special cast irons. Magnitogorsk: GOU VPO "MSTU", 2006. p. 139.

[3] BOBRO, YU. G. Aluminum cast irons. Kharkov: KSU, 1964. p. 195.

[4] PETROV, L.A., BELYAKOV, A.I., TARZHUMANOVA, V.A. Investigation of high-temperature corrosion of cast iron ChS5Sh, ChKh28 and ChYu22Sh. Foundry. 1999, vol. 10, pp. 23-25.

[5] BALIGIDAD, R.G., RADHAKRISHNA, A., SARMA, D.S. Effect of carbon on mechanical properties of Fe-23 wt\% Al alloy. Journal of Materials Science. 2005, vol. 40, pp. 5537-5539.

[6] RADHAVAN, V. Al-C-Fe (Aluminum-Carbon-Iron). Journal of Phase Equilibria and Diffusion. 2007, vol. 28, no. 3, pp. 267-268.

[7] SINNING, H.-R., GOLOVIN, I.S., STRAHL, A., SOKOLOVA, O.A., SAZONOVA, T. Interaction between solute atoms in Fe-Si-Al-C alloys as studied by mechanical spectroscopy. Materials Science and Engineering A. 2009, vol. 521-522, pp. 63-66.

[8] BELOV, V.D., TEN, E.B., DROKIN, A.S. Study of feeding parameters for the production of sound high-alloyed ductile iron castings with aluminum. Key Engineering Materials. 2011, vol. 457, pp. 261-266.

[9] TEN, E.B., DROKIN, A.S. High Aluminum Cast Iron AI22D - Advanced Multifunctional Material. Applied Mechanics and Materials. 2012, vol. 121-126, pp. 186-190.

[10] TEN, E.B., DROKIN, A.S., ASEEV, A.V. Research of aluminum cast iron with spherical graphite CHYu22Sh. Metallurgy of mechanical engineering. 2014, vol. 1, pp. 2-18.

[11] THERMO-CALC SOFTWARE. Thermo-Calc Software. [online]. [viewed 11.12.2020]. Available from: http://www.thermocalc.com. 